\title{
Chemical Fingerprint of Outdoor PM2.5 in Malta
}

M.Balzan ${ }^{1}$, F.Cibella², C. Zammit ${ }^{1}$, D.Bilocca ${ }^{1}$, C.Perrino ${ }^{3}$, S.Canepari ${ }^{4}$, G. Scaccianoce ${ }^{5}$, S.Montefort ${ }^{1}$, G.Viegi ${ }^{2}$ ${ }^{1}$ Mater Dei Hospital - Dept. of Medicine, Malta ${ }^{2}$ National Research Council of Italy, Institute of Biomedicine and Molecular Immunology, Palermo, ${ }^{3}$ Institute of Atmospheric Pollution, National Research Council of Italy, Monterotondo-Rome, Italy, ${ }^{4}$ Chemistry Department, Universita la Sapienza, Rome, Italy, ${ }^{5}$ Engineering department , University of Palermo

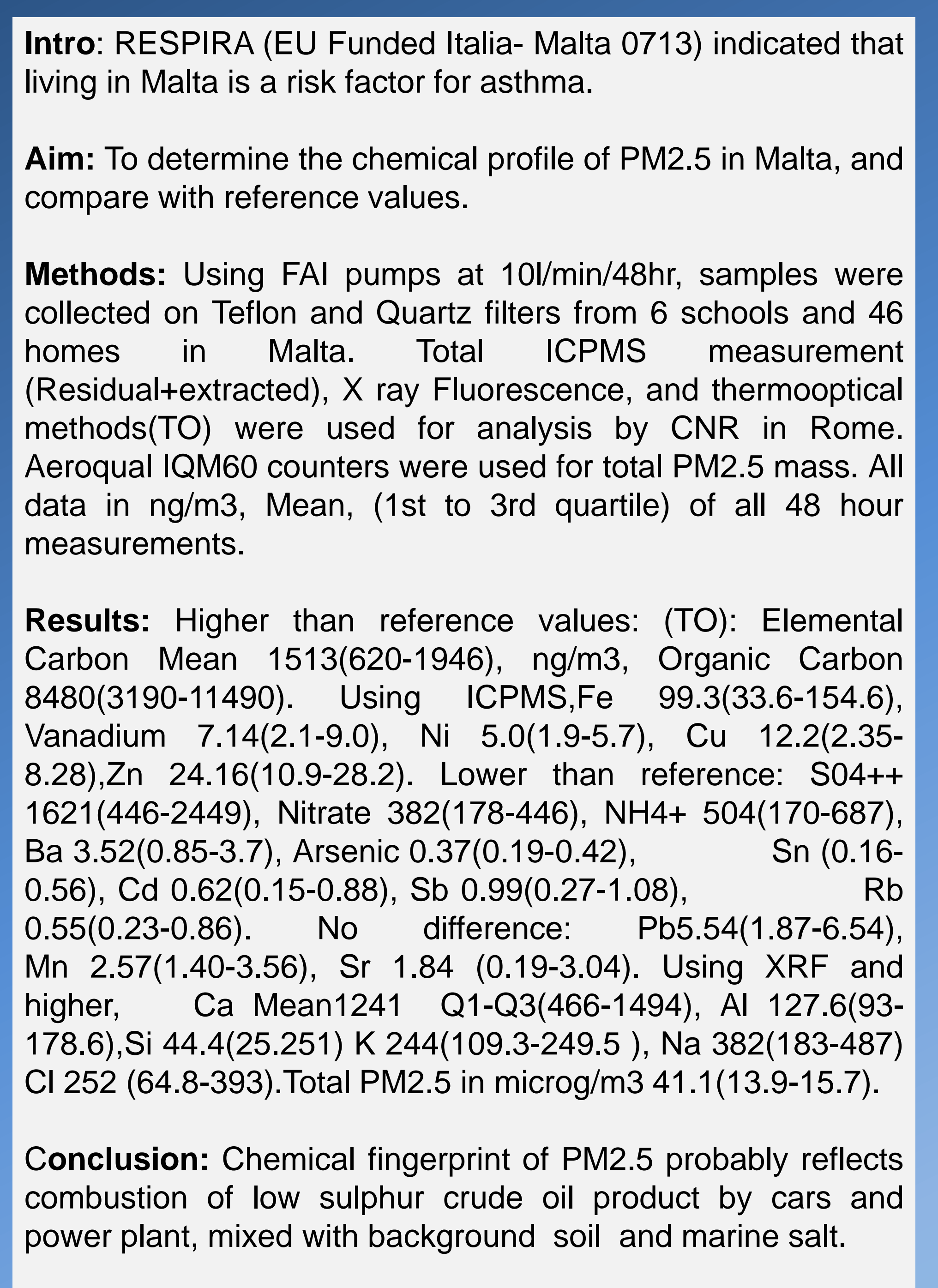

Reference values: 48,591 observations for 187 counties
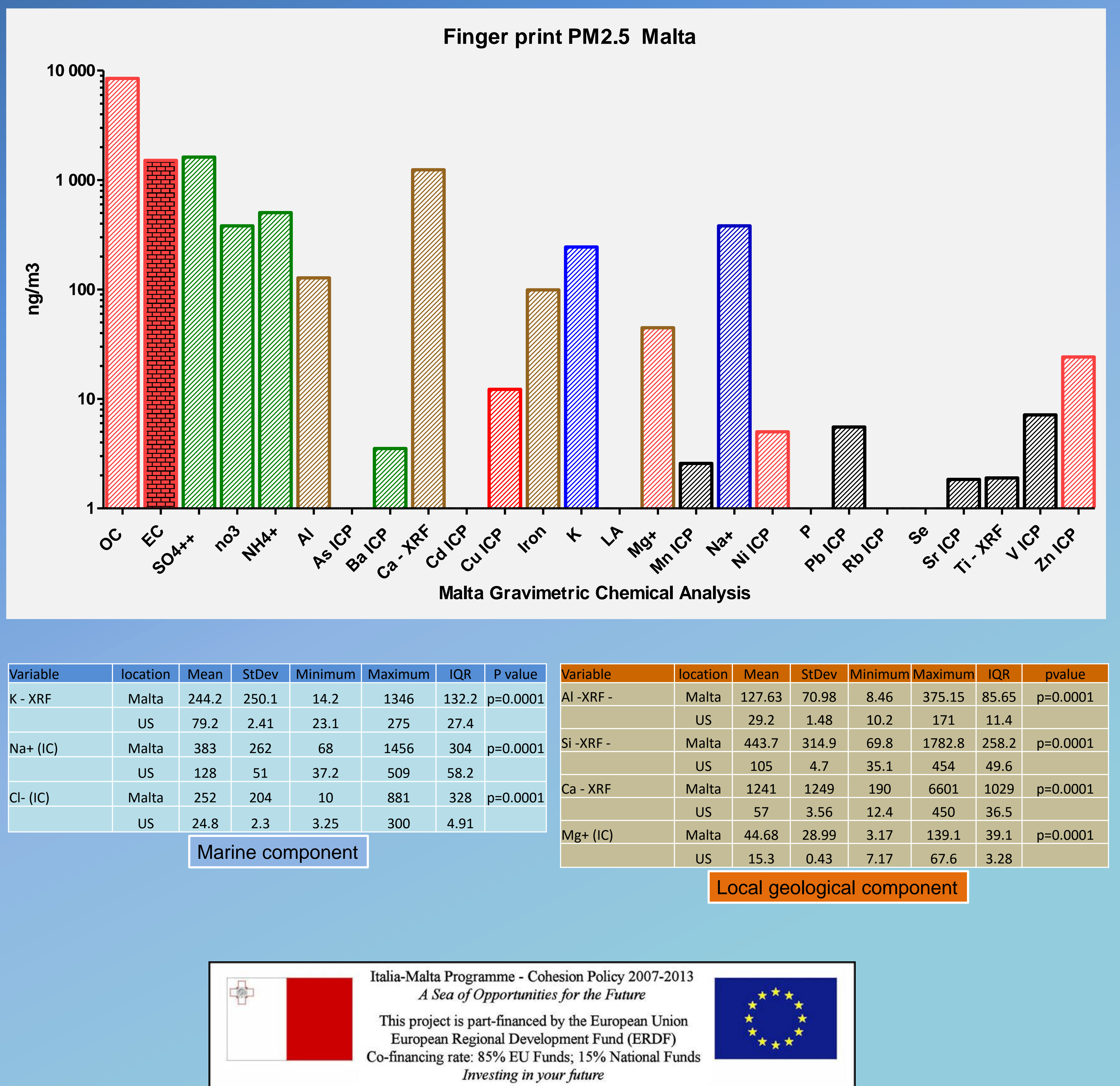

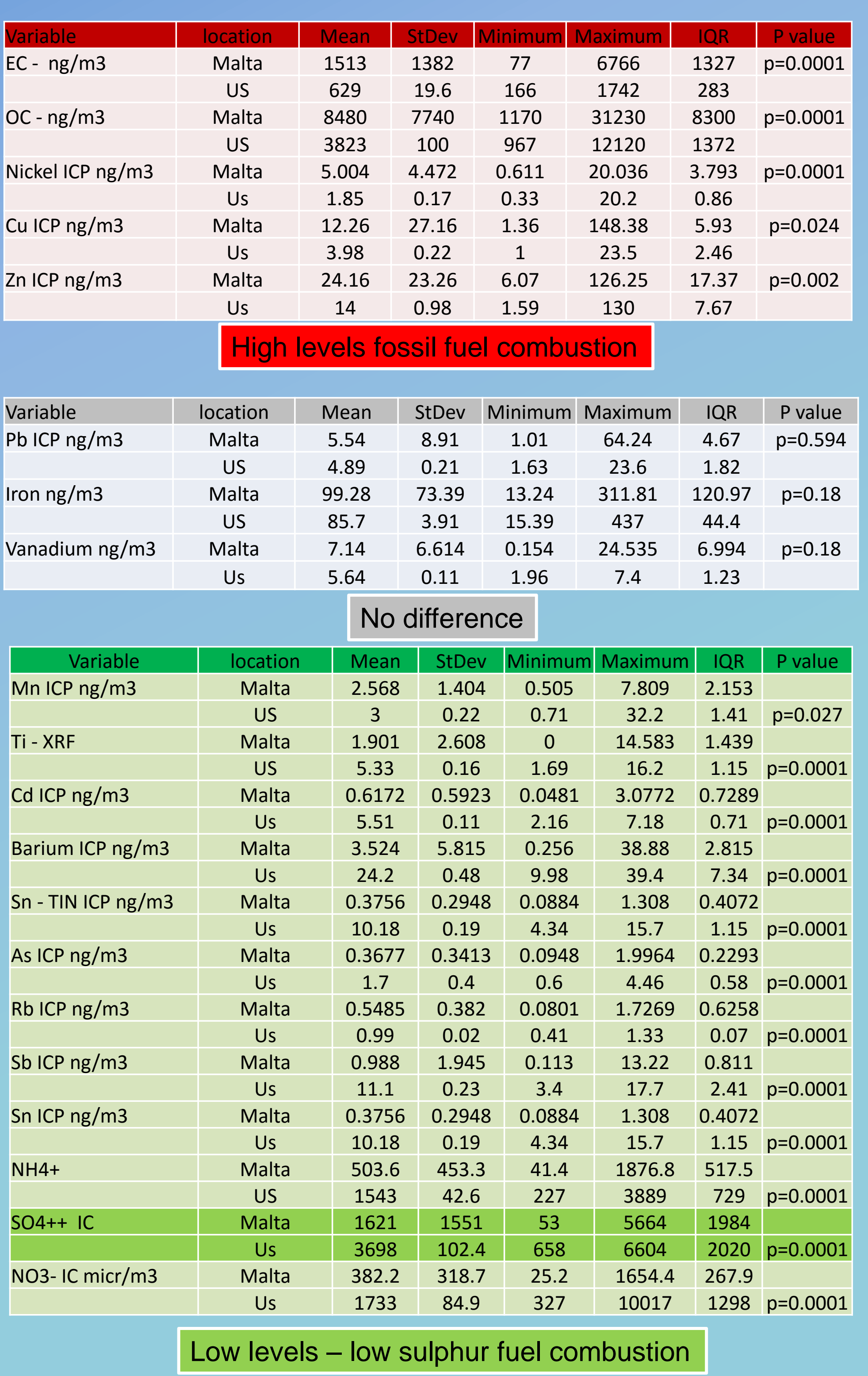

